\title{
Las bombas periféricas... ¡Las bombas olvidadas!
}

Adrián H. D’Ovidio*
Gabriel Perea**
Patricio Glenny****
Laura Titievsky****

*Cardiología e Imagen Cardiovascular. Servicio de Cardiología, Hospital Rawson, San Juan, Argentina

**Cardiología e Imagen Cardiovascular. Instituto Cardiovascular de Buenos Aires, Argentina

***Cardiología e Imagen Cardiovascular, Jeje de Imágenes Cardiovasculares Instituto Cardiovascular Adventista. Buenos Aires, Argentina

****Cardiología e Imagen Cardiovascular. Instituto de Cardiología de Corrientes

Recibido: 21/02/2021

Aceptado: 25/02/2021

En línea: 30/04/2021

Citar como: D'Ovidio A, Perea G, Glenny P, Titievsky L, Las bombas perifericas... jlas bombas olvidadasj Rev Ecocar Pract (RETIC). 2021 (Abril); 4 (1): 48-49. doi: 10.37615/retic.v4n1a13.

Cite this as: D'Ovidio A, Perea G, Glenny P, Titievsky L, Peripheral pumps... The forgotten pumps. Rev Ecocar Pract (RETIC). 2021 (Abril); 4 (1): $48-49$. doi: 10.37615/retic.v4n1a13.

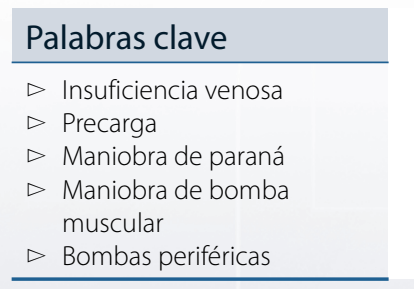

\begin{tabular}{l}
\hline Keywords \\
\hline$\triangleright$ Venous insufficiency \\
$\triangleright$ Preload \\
$\triangleright$ Parana maneuver \\
$\triangleright$ Muscular pump maneuver \\
$\triangleright$ Peripheral pumps \\
\hline
\end{tabular}

\section{RESUMEN}

Se describe la importancia de las masas musculares de los miembros y la utilidad de las maniobras para reducir la presión hidrostática del sistema venoso

\author{
ABSTRACT \\ It is described the usefulness of the limbs muscles and the maneuvers to reduce the hydrostatic pressure
}

En el organismo existen 4 bombas que permiten la adecuada circulación sanguínea':

- La bomba cardíaca

- La bomba diafragmática

- La bomba muscular

- La suela plantar de Lejars

Si a este concepto le agregamos el fundamental juego de presiones (hidrostática, intraabdominal, intratorácica, intrapericárdica, intrapleural, intracardíaca), la indemnidad de las válvulas venosas y las claves distensibilidad aórtica y resistencia periférica, tendremos las claves para entender la precarga y la poscarga cardíaca, sumando el estudio de la contractilidad y la frecuencia cardíaca tendremos la evaluación global de la función ventricular.

En esta "viñeta vascular" me detengo en las "bombas periféricas", fáciles de evaluar clínicamente y con ecografía Doppler venosa, y de importancia práctica enorme.

Todos conocemos que puede padecerse insuficiencia venosa, definida por Franceschi ${ }^{2}$ como "la incapacidad del sistema venoso para asegurar un flujo cardiópeto unidireccional con el débito y presión adaptados a las necesidades del drenaje de los tejidos, -termorregulación y reserva hemodinámica- con independencia de la posición y actividad muscular", por tres mecanismos:
1. La trombosis
2. La incompetencia valvular
3. La falla de las "bombas periféricas"

Para comprender lo anterior, debemos preguntarnos: ¿Por qué es tan importante su evaluación detallada y explicar a nuestros pacientes sencillas maniobras para reducir la presión hidrostática en la columna venosa de los miembros inferiores, particularmente en pantorrillas, tobillos y pies? La respuesta es simple: Porque al estar parados y estáticos, o sentados sin mover las piernas, la presión hidrostática aumenta notablemente, hay estasis sanguínea, extravasación de fluidos, edema, pesadez y dolor. Pensemos en la importancia que puede tener reducir la presión hidrostática venosa distal en algunas actividades laborales y de la vida diaria: policías, ayudantes de odontólogos, oficinistas, viajes prolongados en avión, auto o micros, trabajar horas frente a las computadoras, etc., siendo la lista interminable.

Dos sencillas maniobras permiten reducir la estasis sanguínea, favorecer el retorno venoso y, por lo tanto, en presencia de indemnidad valvular venosa, reducir la signo-sintomatología, son: la "maniobra de Paraná", y la de "bomba muscular"; o ponerse en puntas de pie (Figuras 1 a 3). 


\section{- Trukipedia \\ Truco 01}

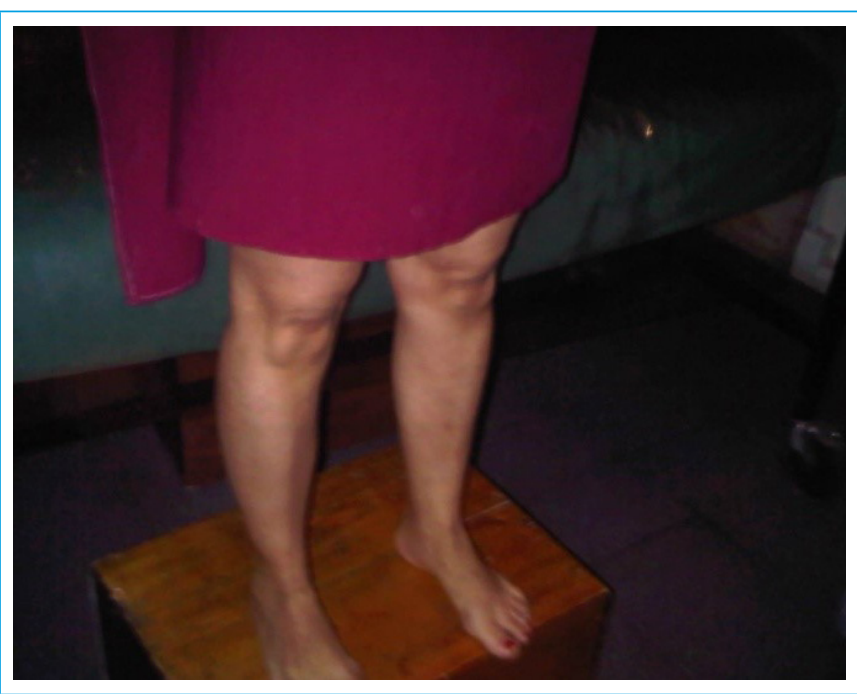

Figura 1. Posición básica

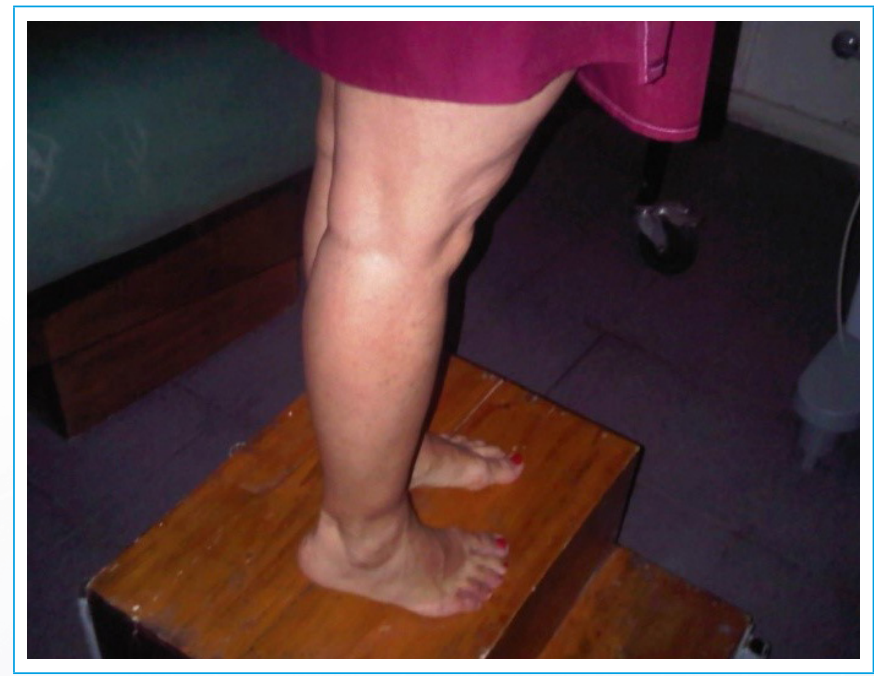

Figura 2. Maniobra de Paraná

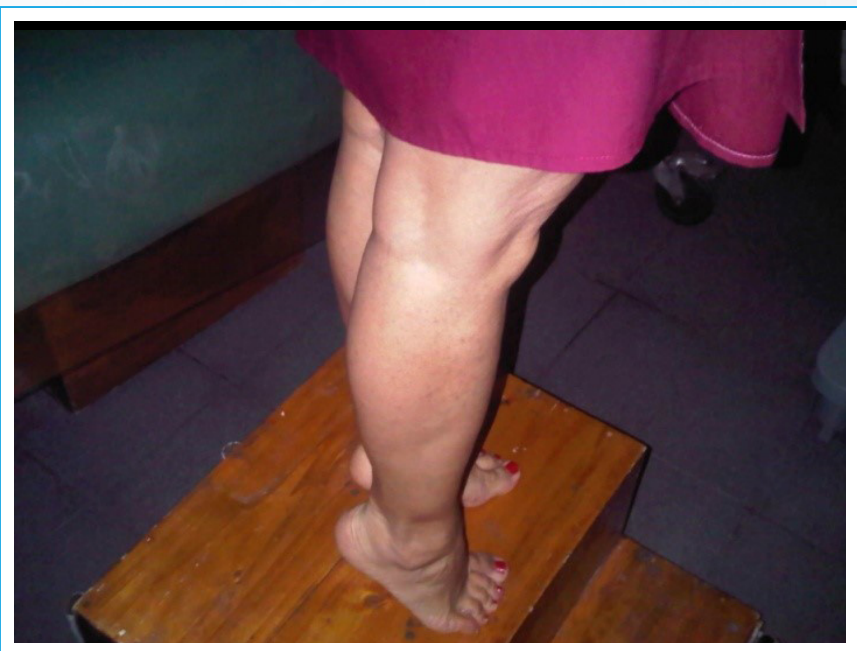

Figura 3. Maniobra de bomba muscular

La maniobra de Paraná consiste en inclinar todo el cuerpo hacia adelante, sin encorvar la cintura, hasta sentir los dedos de los pies, "exprimiendo" la suela plantar de Lejars, lo que permite un flujo centrípeto muy importante, que, en presencia de indemnidad valvular venosa, "vacía" el sistema venoso profundo durante la denominada "sístole de Paraná", reduciendo la presión hidrostática venosa de tobillos y pies. Recordemos el concepto fundamental que, durante la "diástole de Paraná", al reducirse la presión hidrostática venosa en el sistema venoso profundo, se "activan los shunts venosos", la sangre fluye del sistema venoso superficial al profundo y esto reduce a su vez la presión hidrostática sobre las venas del sistema venoso superficial ${ }^{(1,3-7)}$ (Figuras 1 a 3). Además, reducen significativamente la posibilidad de trombosis venosa profunda.

La otra maniobra a tener muy en cuenta es la de "bomba muscular", sencillamente colocando al paciente en "puntas de pie", maniobra que puede efectuarse de pie o sentado (importante para los que trabajan horas sentados, viajes prolongados, etc.), que básicamente comprime y vacía las venas gastrocnemias y sóleas de ambos miembros inferiores, favoreciendo el flujo cardiópeto y reduciendo la presión hidrostática de la columna venosa, con ello, disminuye el edema, la pesadez y el dolor ${ }^{(1,3-7)}$.

Ambas maniobras son efectuadas diariamente al caminar, por ello, resulta tan importante intentar levantarse y caminar unos minutos para reducir la estasis venosa. Al realizar al paciente las maniobras de Paraná y de bomba muscular, apoyados del ecógrafo, podemos constatar lo que ocurre con sus venas: se "Ilenan" las venas del sistema venoso profundo en sístole de Paraná, para "vaciarse" en diástole, al mismo tiempo que las venas gastrocnemias y sóleas se comprimen hasta "no verse" al colocarse el paciente en puntas de pie.

Las anteriores son maniobras sencillas, rápidas, practicables y con resultados seguros y objetivables.

\section{Tips para no olvidar:}

- Activar las "bombas periféricas" (maniobra de Paraná, bombas musculares, o simplemente caminar) reduce la presión hidrostática en el eje venoso de los miembros inferiores y con ello la signo-sintomatología.

- Las maniobras descritas pueden ayudar a prevenir la trombosis venosa profunda.

\section{Bibliografía}

1. Burnard KG and Wadoodi A. The physiology and hemodynamics of chronic venous insufficiency of the lower limb. Glociczki P. Handbook of venous disorders. 3rd. Edition. Hooder Arnold. 2009;Ch. 5:47-69.

2. Franceschi C. Bases hemodinámicas para un mejor diagnóstico y una mejor estrategia terapéutica en la patología vascular arterial y venosa. Conference Paper 2017. www.researchgate.net/publication/320146074.

3. Burnand KG \& Wadoodi A. The physiology and hemodynamics of chronic venous insufficiency of the lower limb. En: Gloviczki P. Handbook of Venous Disorders. 3rd. Ed. Hodder Arnold 2009. Ch. 5:47-55.

4. Berardi $\mathrm{H}$ y Ciccioli A. Examen Doppler de la insuficiencia venosa de miembros inferiores: consenso entre especialistas. Rev Argent Radiol. 2015;79(2):72-79.

5. Padberg F. The physiology and hemodynamics of the normal venous circulation. Gloviczki P. Handbook of venous disorders. Hooder-Arnold. . 2009; Ch.3:25-36.

6. Pietravallo A.F. Introducción y conceptos. En: Pietravallo A.F., Venas perforantes. Clínica, Anatomía y Tratamiento. Univ. Del Salvador. Buenos Aires, Argentina. 2015. Cap. 5.

7. Franceschi C. Mesures et interprétation des flux veineux lors des manoevres de stimulation. Compressions manuelles et manoeuvre de Paraná. Indice dynamique de reflux (IDR) et indice de Psatakis. J Mal Vasc 1997; 22: 91-95. 